\title{
KESAN "PROGRESSIVE MUSCLE RELAXATION" (PMR) KE ATAS TEKANAN EMOSI DALAM KALANGAN PEMAIN BOLA JARING 10 DAN 11 TAHUN
}

\author{
Wan Nur Najiah Wan Abd Ghani, Nur Ilyani Ishak \& Nelfianty Mohd Rasyid
}

Fakulti Sains Sukan dan Kejurulatihan, Universiti Pendidikan Sultan Idris, Malaysia

Jurnal Sains Sukan dan Pendidikan Jasmani 8(1) 39-44, Received: 23 Mei 2019, Accepted: 16 Jun 2019

DOI: https://doi.org/10.37134/jsspj.vol8.1.5.2019

\begin{abstract}
Abstrak
Kajian ini dijalankan untuk mengenalpasti kesan latihan kemahiran psikologi Progressive Muscle Relaxation (PMR) ke atas tekanan emosi dalam kalangan pemain bola jaring berumur 10 dan 11 tahun. Sampel kajian adalah terdiri daripada 10 orang pemain yang berumur 10 tahun dan 10 orang berumur 11 tahun $(\mathrm{N}=20)$. Data kajian ini diperoleh melalui skor borang soal selidik Depression Anxiety Stress Scale-21 (DASS-21) untuk mengukur tahap tekanan emosi. Analisis nilai min dan peratusan digunakan untuk melihat tahap tekanan emosi manakala ujian Mixed Anova digunakan untuk mengkaji kesan latihan PMR terhadap kumpulan rawatan iaitu pemain bola jaring yang menyertai Karnival Tunas Mini Olimpik (KATMO). Subjek dibahagikan kepada kumpulan kawalan yang menjalani sesi menyejukkan badan seperti biasa manakala kumpulan rawatan menjalani PMR. Hasil kajian menunjukkan perbezaan kesan yang signifikan antara skor kumpulan kawalan dan rawatan, $F(1,18)=50.22$, $p$ $=.00, \eta p 2=0.74$ ) di mana kumpulan rawatan didapati berjaya menurunkan skor stress, kebimbangan dan kemurungan dengan lebih banyak. Oleh yang demikian, jurulatih dan atlet harus memberi tumpuan terhadap latihan relaksasi untuk mengatasi masalah tekanan emosi dan kebimbangan untuk membantu dalam mencapai prestasi puncak.
\end{abstract}

Kata kunci: pemain bola jaring, DASS-21, tekanan emosi, kebimbangan, latihan relaksasi.

\section{THE EFFECT OF PROGRESSIVE MUSCLE RELAXATION (PMR) ON EMOTIONAL DISTRESS AMONG 10 AND 11 YEARS OLD NETBALL PLAYERS}

\begin{abstract}
This study examined the effects of psychological skill training of Progressive Muscle Relaxation (PMR) on emotional distress among 10 and 11 years old netball players. The sample consisted of 10 players aged 10 years old and the other 10 aged 11 years old $(n=20)$. The data was obtained through the Depression Anxiety Stress Scale-21 questionnaire (DASS-21) to measure the level of emotional stress. The mean and percentage value analysis is used to see the emotional stress level while the Mixed Anova test is used to study the impact of PMR training on the treatment group i.e. the netball player who participated in the Karnival Tunas Mini Olimpik (KATMO). Subjects were divided into control group that underwent normal cooling down session while treatment group underwent PMR. Results showed a significant different effects between control and treatment group, F(1, $18)=50.22, p=.00, \eta p 2=0.74$, with treatment group was found to reduce the stress, anxiety and depression more than the control group. Therefore, coaches and athletes should focus on relaxation training as a way to solve emotional stress problem and anxiety to help in achieving peak performance.
\end{abstract}

Keywords: netball players, DASS-21, emotional distress, anxiety, relaxation training. 


\section{PENGENALAN}

Tekanan emosi merupakan salah satu istilah biasa dalam sukan yang digunakan oleh atlet, jurulatih, penonton dan media. Kekuatan mental dan kesediaan bertanding adalah dua aspek psikologi yang perlu ada dalam setiap atlet bagi mencapai prestasi yang diharapkan. Kekuatan mental adalah aspek penting yang akan membawa kepada pencapaian dalam prestasi seseorang atlet. Walau bagaimanapun, ia juga salah satu istilah yang kurang difahami (Sheard, 2013). Individu hanya mampu mentafsirkan tekanan emosi dalam sukan seperti mengalami kebimbangan kerana bertemu dengan lawan yang lebih kuat, menjadi agresif kerana dikasari pihak lawan manakala kekuatan mental adalah cara atlet menguruskan keperluan untuk mempamerkan prestasi tinggi dalam sesuatu sukan dan dalam situasi yang tegang supaya dapat mencapai kejayaan (Anthony, Gucciardi, \& Gordon, 2016; Connaughton et al., 2010; Gucciardi \& Gordon, 2011).

Oleh yang demikian, atlet dan jurulatih perlu mengetahui latihan relaksasi yang boleh diaplikasikan semasa mereka menjalani latihan atau semasa dalam situasi pertandingan. Kajian lepas telah mengenal pasti latihan relaksasi yang berkesan dalam mengawal tekanan emosi (Hashim \& Zainol, 2015). Latihan relaksasi otot progresif atau progressive muscle relaxation (PMR) merupakan kaedah untuk merehatkan minda dan badan melalui latihan psikologi. Teknik PMR ini dikembangkan oleh seorang doktor daripada Amerika Syarikat iaitu Edmund Jacobson pada awal tahun 1929. Menurut Herodes (2010), teknik relaksasi otot progresif adalah teknik relaksasi otot dalaman yang tidak memerlukan imaginasi dan ketekunan.

Srilekha, Soumendra dan Chattopadhyay (2013) dalam kajian mereka, latihan PMR yang digunakan sebagai intervensi terapeutik untuk jangka masa yang pendek adalah berkesan dalam memanipulasi emosi yang memuncak, mengurangkan kebimbangan dan meningkatkan prestasi dalam kalangan kanak-kanak di India. Kenyataan ini disokong oleh (Jaworska, Hawrylak, Burzynski, \& Gieracha, 2015) di mana latihan relaksasi ini membawa kepada pengurangan kebimbangan dan mengurangkan risiko kecederaan disebabkan oleh tekanan emosi atlet.

Tekanan emosi dalam kalangan kanak-kanak yang melibatkan diri dalam sukan adalah bukan satu perkara yang baharu. Antara pengkaji yang mengenal pasti kesan tekanan emosi oleh atlet muda adalah kajian oleh Jaworska, Hawrylak, Burzynski, dan Gieracha (2015) iaitu atlet muda akan lebih terdedah kepada tekanan berbanding dengan atlet yang lebih tua di mana ini kemungkinan menjadi penyebab mengapa kecederaan kerap berlaku dalam kalangan atlet muda. Hal tersebut berlaku mungkin kerana mereka kurang mahir mengendalikan tekanan emosi semasa menghadapi pertandingan atau semasa menjalani latihan. Berdasarkan kajian dalam perkembangan psikologi, kanak-kanak yang berumur hampir 12 tahun sedang menuju ke tempoh kritikal dengan kesan penting terhadap personaliti dan perkembangan psikologi mereka juga disebabkan oleh pengalaman dalam sukan (Weinberg \& Gould, 2011).

Dalam kajian-kajian yang lepas latihan relaksasi boleh menyebabkan keupayaan kognitif seseorang menjadi tenang. Justeru itu, objektif kajian ini adalah untuk melihat kesan latihan relaksasi PMR dalam kalangan pemain bola jaring berumur 10 dan 11 tahun yang akan bermain dalam Karnival Tunas Mini Olimpik (KATMO). Kejohanan ini merupakan pertandingan yang mencungkil bakat pemain-pemain muda dalam daerah Hulu Langat, Selangor. Persoalan yang wujud dalam kajian ini ialah apakah kesan PMR kepada tekanan emosi (kemurungan, kebimbangan dan stress).

\section{METODOLOGI}

\section{Reka bentuk kajian}

Kajian ini berbentuk kuasi eksperimental. Data untuk dianalisis diperoleh menerusi borang soal selidik Depression Anxiety Stress Scale-21 (DASS-21) yang diedarkan kepada peserta kajian semasa ujian pra dan pasca. 


\section{Pemilihan peserta kajian}

Peserta kajian terdiri daripada 20 orang pemain bola jaring berumur 10 tahun $(\mathrm{N}=10)$ dan 11 tahun $(\mathrm{N}=10)$. Peserta kajian adalah terdiri daripada pemain bola jaring sekolah rendah yang menyertai Karnival Tunas Mini Olimpik (KATMO) 2018 Daerah Hulu Langat, Selangor.

\section{Instrumen}

\section{Skrip Progressive Muscle Relaxation (PMR)}

Skrip PMR digunakan sebagai intervensi terhadap kumpulan rawatan yang berdurasi selama 30 minit. Arahan relaksasi yang digunakan dalam kajian ini adalah berdasarkan kepada skrip yang telah digubal oleh Williams (2010). Cara penyampaian skrip adalah dengan nada yang perlahan, jelas dan arahan yang ringkas serta mudah difahami. Arahan skrip disampaikan oleh pengkaji sendiri.

\section{Depression Anxiety Stress Scale-21 (DASS-21)}

Borang DASS-21 yang telah diterjemah ke dalam Bahasa Malaysia dan mendapat kesahan (nilai Cronbach's alpha $.84, .74$ and .79 , untuk kemurungan, kebimbangan dan stress) digunakan untuk mengukur tahap kemurungan, kebimbangan dan tahap stress (Hashim, Freddy, \& Rosmatunisah, 2012). Peserta kajian diminta untuk mengenal pasti sejauh mana simptom yang diukur dalam pernyataan soal selidik tersebut yang berlaku kepada diri mereka semasa ujian pra dan ujian pasca. Maklum balas dilampirkan pada skala Likert 4 mata bermula dari 0 (tidak pernah sama sekali) hingga 3 (sangat kerap).

\section{Prosedur Kajian}

Kebenaran telah diperoleh daripada pihak sekolah dan peserta kajian iaitu murid sekolah serta ibu bapa mereka juga telah dimaklumkan tentang tujuan kajian yang akan dijalankan. Pengkaji akan menjalankan kajian semasa latihan harian iaitu sebanyak tiga hari selama tiga minggu. Semasa ujian pra, para pemain diminta mengisi borang soal selidik DASS-21. Mereka menjawab soal selidik tersebut selama lebih kurang 10 minit dengan bantuan penolong pengkaji apabila diperlukan. Selepas ujian pra dijalankan, mereka dibahagikan secara rawak kepada dua kumpulan iaitu rawatan latihan relaksasi PMR $(\mathrm{N}=10)$ dan kawalan $(\mathrm{N}=10)$.

Peserta kajian latihan relaksasi diperdengarkan dengan bacaan skrip PMR dalam Bahasa Melayu selama 30 minit setiap kali selepas habis latihan harian. Latihan dijalankan sebanyak tiga kali seminggu, selama tiga minggu. Mereka diminta untuk duduk di atas kerusi dalam keadaan yang selesa. Sesi ini dijalankan di dalam makmal komputer yang berhawa dingin pada suhu 27 darjah. Mereka perlu membuka kasut dan memakai pakaian yang selesa semasa latihan relaksasi dijalankan. Para peserta diingatkan supaya memberi tumpuan sepenuhnya terhadap arahan yang diberikan. Mereka diminta mengikuti arahan dan melakukan pergerakan yang terkandung dalam arahan tersebut. Pengkaji juga mengingatkan peserta kajian agar mengelakkan segala perbincangan serta interaksi semasa PMR dijalankan. Manakala kumpulan kawalan terlibat dalam sesi refleksi selepas latihan seperti biasa. Akhir sekali, semasa ujian pasca mereka akan mengisi borang DASS-21 setelah menjalani latihan PMR selama tiga minggu.

\section{Analisis Statistik}

Data yang diperoleh dikumpulkan dan dianalisis menggunakan perisian Statistic Package for the Social Science (SPSS) versi 20. Statistik inferens digunakan untuk menerangkan hubungan latihan relaksasi PMR dengan DASS-21 (stress, kebimbangan, kemurungan) menggunakan ujian mixed Anova. Tahap signifikan telah disetkan pada $p<.05$. 


\section{DAPATAN KAJIAN}

Statistik deskriptif yang mewakili dapatan ujian pra dan ujian pasca untuk kumpulan kawalan dan PMR dipersembahkan dalam Jadual 1. Skor tekanan emosi dikategorikan kepada normal, ringan, sederhana, teruk dan sangat teruk (Lovibond \& Lovibond, 1995). Taburan kekerapan skor tersebut dapat dilihat dalam Jadual 2.

Keputusan analisis ujian mixed Anova menunjukkan terdapat perbezaan yang signifikan secara keseluruhan, $\mathrm{F}(5,90)=107.307, \mathrm{p}=.00, \eta \mathrm{p} 2>.001$ dalam skor stress $(\mathrm{M}=6.8, \mathrm{SD}=1.64)$, kebimbangan $(\mathrm{M}=8.75, \mathrm{SD}=1.58)$ dan kemurungan $(\mathrm{M}=4.05, \mathrm{SD}=1.31)$ ketika ujian pra dan pasca. Selain itu, terdapat perbezaan kesan yang signifikan antara skor kumpulan kawalan dengan kumpulan rawatan, $\mathrm{F}(1,18)=50.22, \mathrm{p}=.00, \eta \mathrm{p} 2=0.74)$ dimana didapati kumpulan rawatan dapat menurunkan skor stress, kebimbangan dan kemurungan dengan lebih banyak.

Jadual 1. Skor Min dan Sisihan Piawai Semasa Ujian Pra dan Ujian Pasca Mengikut Kumpulan

\begin{tabular}{lcc}
\hline & PMR $(\mathbf{N}=\mathbf{1 0})$ & Kawalan $(\mathbf{N}=\mathbf{1 0})$ \\
\hline Ujian Pra & & \\
Stress & $9.30 \pm 1.34$ & $8.10 \pm 1.10$ \\
Kebimbangan & $12.60 \pm 1.43$ & $11.60 \pm 2.17$ \\
Kemurungan & $4.00 \pm 1.25$ & $5.40 \pm 0.84$ \\
\hline & PMR (N=10) & Kawalan $(\mathbf{N}=\mathbf{1 0})$ \\
\hline Ujian Pasca & & \\
Stress & $5.50 \pm 0.85$ & $10.10 \pm 1.10$ \\
Kebimbangan & $7.50 \pm 0.81$ & $5.10 \pm 0.74$ \\
Kemurungan & $3.00 \pm 0.65$ & \\
\hline
\end{tabular}

Jadual 2. Taburan Kekerapan Tekanan Emosi Berdasarkan Kumpulan (Ujian Pasca)

\begin{tabular}{llccc}
\hline & & Kemurungan & Kebimbangan & Stress \\
\hline Normal & Skor saringan & $0-5$ & $0-4$ & $0-7$ \\
& Kawalan & $70 \%$ & & $20 \%$ \\
Ringan & PMR & $100 \%$ & & $100 \%$ \\
& Skor saringan & $6-7$ & $5-6$ & $8-9$ \\
& Kawalan & $30 \%$ & & $70 \%$ \\
Sederhana & PMR & & $20 \%$ & $10-13$ \\
& Skor saringan & $8-10$ & $7-8$ & $10 \%$ \\
Teruk & Kawalan & & & $14-17$ \\
& PMR & & $60 \%$ & \\
& Skor saringan & $11-14$ & $9-10$ & $18+$ \\
Sangat Teruk & Kawalan & & $70 \%$ & \\
& PMR & & $20 \%$ & \\
& Skor saringan & $15+$ & $30 \%$ & \\
& Kawalan & & & \\
& PMR & & & \\
& & & & \\
& & & & \\
\end{tabular}




\section{PERBINCANGAN DAN KESIMPULAN}

Sukan boleh menjadi satu bidang yang memberi tekanan bukan sahaja kepada atlet malah jurulatih juga kerana individu yang terlibat dalam sukan mesti memenuhi beberapa keperluan dan berkebolehan untuk mengatasi pelbagai jangkaan (Norris, Didymus, \& Kaiseler, 2017). Tambahan lagi, atlet atau pemain yang muda cenderung untuk mengalami tempoh tekanan emosi sepanjang penglibatan mereka dalam sukan. Atlet muda wanita dilaporkan mengalami tekanan emosi yang lebih signifikan berbanding dengan atlet lelaki (Britton, Kavanagh, \& Polman, 2017). Intervensi untuk mengurangkan kesan negatif daripada tekanan emosi adalah sangat diperlukan (Hashim \& Zainol, 2015) supaya atlet boleh kekal fokus dalam prestasi sukan yang disertainya. Hasil dapatan kajian ini menunjukkan perubahan skor min yang signifikan dalam ketiga-tiga ujian yang terkandung dalam DASS-21. Dapatan ini mungkin boleh dikaitkan dengan keinginan pemain untuk mengawal emosi yang kadangkala mengganggu prestasi mereka. Latihan relaksasi PMR yang dilaksanakan oleh pengkaji telah menjadi penyebab perubahan skor min antara kumpulan PMR dgn kawalan. Tambahan pula, penggunaan teknik relaksasi yang bebas mungkin tidak berkesan berbanding dengan teknik yang spesifik terhadap kanak-kanak (Lohaus, KleinHebling, Vogele, \& Kuhn-Hennighausen, 2001).

Hasil skor saringan ujian kebimbangan dalam DASS-21 menunjukkan bahawa kebimbangan menjadi penyumbang utama kepada tekanan emosi yang berlaku dalam kalangan pemain bola jaring yang berumur 10 dan 11 tahun. Seperti yang ditunjukkan dalam Jadual 2, sebanyak 70\% pemain dalam kumpulan kawalan yang mengalami kebimbangan pada tahap teruk. Kebimbangan adalah satu tindak balas emosi yang popular dalam sesuatu lakuan sukan. Hal ini berlainan dengan ujian kemurungan dan stress di mana tiada pemain yang dilaporkan mengalami dua perkara ini pada tahap yang teruk cuma hanya $10 \%$ pemain mengalami stress pada tahap sederhana. Kajian Gould et al. (2002) merungkai ciriciri kemahiran mental atlet sukan Olimpik adalah terdiri daripada keupayaan daya tindak balas, kawalan kebimbangan dan sebagainya. Kawalan kebimbangan adalah salah satu kemahiran mental yang perlu dikuasai oleh atlet jika ingin mencapai prestasi puncak dalam sukan yang diceburi.

Pemain dalam kumpulan rawatan mungkin memerlukan lebih banyak sesi latihan relaksasi untuk membolehkan mereka menguasai sepenuhnya teknik yang dilaksanakan supaya kesannya lebih memuaskan pada masa akan datang. Ini disokong dengan kajian yang dijalankan oleh Hanafi et al., (2011) iaitu kajian dalam kalangan atlet remaja Malaysia yang diperhatikan bahawa 12 sesi PMR yang setiap satunya berdurasi 30 minit diperlukan untuk menghasilkan perbezaan dari segi psikomotor dan fisiologi.

Kajian menunjukkan kombinasi latihan mental dan fizikal memberi kesan yang lebih signifikan berbanding jika hanya melakukan latihan fizikal semata-mata (Kumar \& Shirotriya, 2010). Dengan itu, pengkaji dapat mengutamakan aspek kebimbangan dan menekankan kepentingan PMR dalam merangka sesi latihan berkesan yang melibatkan penggunaan relaksasi untuk mengurangkan tekanan emosi tersebut.

\section{RUJUKAN}

Anthony, D. R., Gucciardi, D. F., \& Gordon, S. (2016). A meta-study of qualitative research on mental toughness development. International Review of Sport and Exercise Psychology, 9(1), 160-190.

Britton, D., Kavanagh, E., \& Polman, R. (2017). The perceived stress reactivity scale for adolescent athletes. Personality and Individual Differences, 301-308.

Connaughton, D., Hanton, S., \& Jones, G. (2010). The development and maintenance of mental toughness in the world's best performers. The Sport Psychologist, 24(2), 168-193.

Gould, D., Dieffenbach, K., \& Moffett, A. (2002). Psychological characteristics and their development in Olympic champions. Journal of Applied Sport Psychology, 14, 172-204.

Hanafi, H., Hashim, H. A., \& Ghosh, A. (2011). Comparison of long term effects of two types of relaxation techniques on choice reaction time and selected psychophysiological variables following repeated sub-maximal intensity exercises in school level athletes. International Journal of Applied Sport Science, 23, 183-197. 
Hashim, H. A., \& Zainol, N. A. (2015). Changes in emotional distress, short term memory, and sustained attention following 6 and 12 sessions of progressive muscle relaxation training in 10-11 years old primary school children. Psychology, Health \& Medicine, 623-628.

Hashim, H. A., Freddy, G., \& Rosmatunisah, A. (2012). Relationships Between Negative Affect and Academic Achievement Among Secondary School Students: The Mediating Effects of Habituated Exercise. Journal of Physical Activity and Health, 1012-1019.

Herodes, R. (2010). Anxiety and Depression in Patient.

Lohaus, A., Klein-Heßling, J., Vögele, C., \& Kuhn-Hennighausen, C. (2001). Psychophysiological effects of relaxation training in children. British Journal of Health Psychology, 6, 197206.doi:10.1348/135910701169151

Jaworska, L., Hawrylak, A., Burzynski, B., \& Gieracha, J. S. (2015). Effect of progressive muscle relaxation on pain threshold and effectiveness of footballers training. Human Movement, $225-$ 228.

Kumar, P. \& Shirotriya, A. K. (2010). "Sports psychology"e a crucial ingredient for athlete success: Conceptual view. British Journal of Sports Medicine, 44(1), i55-i56.

Lovibond, S.H. \& Lovibond, P.F. (1995). Manual for the Depression Anxiety Stress Scales. (2nd. Ed.) Sydney: Psychology Foundation.

Norris, L. A., Didymus, F. F., \& Kaiseler, M. (2017). Stressors, coping, and well-being among sports coaches: A systematic review. Psychology of Sport and Exercise, 93-112.

Srilekha, S., Soumendra, S., \& Chattopadhyay, P. K. (2013). Effect of muscle relaxation training as a function of improvement in attentiveness in children. Procedia-Social and Behavioral Sciences, 91, 606-613.

Sheard, M. (2013). Mental Toughness : The Mindset Behind Sporting Achievement. New York: Routledge.

Weinberg, R. S., \& Gould, D. (2011). Children and Sport Psychology. In R. S. Weinberg, \& D. Gould, Foundations of Sport and Exercise Psychology (p. 516). United States: Human Kinetics.

Williams, J. M. (2010). Relaxation and Energizing Techniques for Regulation of Arousal. In J. M. Williams, Applied Sport Psychology : Personal Growth to Peak Performance (pp. 254-256). New York: McGraw-Hill.

Wilson, D., Bennett, E., Mosewich, A., Faulkner, G., \& Crocker, P. (2018). "The zipper effect": Exploring the interrelationship of mental toughness and self-compassion among Canadian elite women athletes. Psychology of Sport \& Exercise, 61-70.

\author{
”- Wan Nur Najiah binti Wan Abd Ghani \\ Faculty of Sports Science and Coaching \\ Universiti Pendidikan Sultan Idris \\ 35900 Tg Malim, Perak \\ MALAYSIA
}

E-mail: wannajiah93@gmail.com 